\title{
Validation of prospective portion size and latency to eat as measures of reactivity to snack foods
}

Citation for published version (APA):

van den Akker, K., Bongers, P., Hanssen, I., \& Jansen, A. (2017). Validation of prospective portion size and latency to eat as measures of reactivity to snack foods. Appetite, 116, 480-486. https://doi.org/10.1016/j.appet.2017.05.049

Document status and date:

Published: 01/09/2017

DOI:

10.1016/j.appet.2017.05.049

Document Version:

Publisher's PDF, also known as Version of record

Document license:

Taverne

\section{Please check the document version of this publication:}

- A submitted manuscript is the version of the article upon submission and before peer-review. There can be important differences between the submitted version and the official published version of record.

People interested in the research are advised to contact the author for the final version of the publication, or visit the DOI to the publisher's website.

- The final author version and the galley proof are versions of the publication after peer review.

- The final published version features the final layout of the paper including the volume, issue and page numbers.

Link to publication

\footnotetext{
General rights rights.

- You may freely distribute the URL identifying the publication in the public portal. please follow below link for the End User Agreement:

www.umlib.nl/taverne-license

Take down policy

If you believe that this document breaches copyright please contact us at:

repository@maastrichtuniversity.nl

providing details and we will investigate your claim.
}

Copyright and moral rights for the publications made accessible in the public portal are retained by the authors and/or other copyright owners and it is a condition of accessing publications that users recognise and abide by the legal requirements associated with these

- Users may download and print one copy of any publication from the public portal for the purpose of private study or research.

- You may not further distribute the material or use it for any profit-making activity or commercial gain

If the publication is distributed under the terms of Article $25 \mathrm{fa}$ of the Dutch Copyright Act, indicated by the "Taverne" license above, 


\title{
Validation of prospective portion size and latency to eat as measures of reactivity to snack foods
}

\author{
Karolien van den Akker ${ }^{*},{ }^{1}$, Peggy Bongers ${ }^{* *}, 1$, Imke Hanssen, Anita Jansen \\ Faculty of Psychology and Neuroscience, Maastricht University, CPS, Department of Eating Disorders and Obesity, P.O. Box 616 6200 MD Maastricht, The \\ Netherlands
}

\section{A R T I C L E I N F O}

\section{Article history:}

Received 7 December 2016

Received in revised form

10 May 2017

Accepted 27 May 2017

Available online 29 May 2017

\section{Keywords:}

Prospective portion size

Latency to eat

Cue reactivity

Food intake

\begin{abstract}
A B S T R A C T
In experimental studies that investigate reactivity to the sight and smell of highly palatable snack foods, ad libitum food intake is commonly used as a behavioural outcome measure. However, this measure has several drawbacks. The current study investigated two intake-related measures not yet validated for food cue exposure research involving common snack foods: prospective portion size and latency to eat. We aimed to validate these measures by assessing prospective portion size and eating latencies in female undergraduate students who either underwent snack food exposure or a control exposure. Furthermore, we correlated prospective portion size and latency to eat with commonly used measures of food cue reactivity, i.e., self-reported desire to eat, salivation, and ad libitum food intake. Results showed increases in prospective portion size after food cue exposure but not after control exposure. Latency to eat did not differ between the two conditions. Prospective portion size correlated positively with desire to eat and food intake, and negatively with latency to eat. Latency to eat was also negatively correlated with desire to eat and food intake. It is concluded that the current study provides initial evidence for the prospective portion size task as a valid measure of reactivity to snack foods in a Dutch female and mostly healthy weight student population.
\end{abstract}

๑) 2017 Elsevier Ltd. All rights reserved.

\section{Introduction}

Exposure to the sensory properties of palatable foods (e.g., their sight and smell) stimulates appetitive responses, including a heightened desire to eat as well as 'cephalic phase' responses that serve to prepare an organism for the digestion and metabolism of food (Nederkoorn, Smulders, \& Jansen, 2000; Power \& Schulkin, 2008). Collectively, responses to food cues are termed food cue reactivity, and it is thought that this reactivity stimulates food intake (Boswell \& Kober, 2016; Jansen, 1998; Jansen, Havermans, \& Nederkoorn, 2011). This behavioural consequence of food cue exposure is important given that overeating is a main contributor to obesity.

To measure food intake after food cue exposure, experimental studies commonly use an ad libitum food intake test (often presented as a 'taste test'), in which participants are presented with generously filled bowls containing snack foods of which participants can eat as much as they like. However, assessing behavioural reactivity to snack food exposure this way has some limitations. First, it has been argued that the presence of the sight, smell, and taste of food during an ad libitum food intake test is a strong form of cue exposure in itself, which may diminish the differences between the cued (i.e., exposure to food cues) and control (i.e., exposure to neutral objects) conditions (Tetley, Brunstrom, \& Griffiths, 2009, 2010). This could explain why several studies failed to find increased intake after food cue exposure compared to a control condition (Larsen, Hermans, \& Engels, 2012; Nederkoorn \& Jansen, 2002; Zoon, He, de Wijk, de Graaf, \& Boesveldt, 2014). Second, while ad libitum food intake induces satiation, it can arguably only be assessed once during an experimental session and after the other outcome measures have been administered. As a result, no baseline or repeated measures can be obtained, reducing power

\footnotetext{
* Corresponding author.

** Corresponding author

E-mail addresses: karolien.vandenakker@maastrichtuniversity.nl (K. van den Akker), peggy.bongers@maastrichtuniversity.nl (P. Bongers).

1 The first two authors contributed equally to the manuscript.
} 
and limiting its applicability. Third, it can be questioned whether the "unlimited" amount of food in a typical ad libitum intake test accurately reflects most instances of food intake in the natural environment (Ferriday \& Brunstrom, 2008). Finally, laboratory eating behaviour may be particularly susceptible to participant's awareness of being monitored. In a recent meta-analysis (Robinson, Hardman, Halford, \& Jones, 2015), it was shown that in healthyweight females (a commonly used sample in eating research) both belief and knowledge of observation of their eating behaviour reduced food intake in the laboratory.

It has been proposed that an important determinant of food intake within one eating occasion is the amount of food one plans to eat (Brunstrom, 2011; 2014), for example by influencing the amount of food that one prepares and serves. This pre-meal planning of portion sizes has previously been assessed in experiments using a computerized task (the prospective portion size task or PPST; e.g., Ferriday \& Brunstrom, 2008; Holliday, Batey, Eves, \& Blannin, 2014; Wilkinson et al., 2012), in which participants can adjust the amount of food they wish to eat on a virtual plate. Unlike an ad libitum food intake test, the PPST does not induce satiation (allowing for its repeated administration), and its assessment may not elicit as much cue reactivity (potentially increasing its sensitivity). In support of its validity in food cue reactivity paradigms, several prior studies have demonstrated increases in prospective portion sizes of a cued food after exposure to its sight and smell (Ferriday \& Brunstrom, 2008, 2011; Tetley, Brunstrom, \& Griffiths, 2010). However, the cued food in these studies was restricted to pizza. To our knowledge, it has never been studied whether prospective portion size of common snack foods increases after snack food exposure, even though food cue reactivity studies very often involve exposure to high-calorie snack foods, as this is the type of food obese individuals and dieters usually struggle to refrain from eating. Therefore, validating the PPST involving snack foods in food cue reactivity paradigms is of importance.

Exposure to food cues likely increases food intake not only through increasing the size of eaten meals and snacks but also by promoting their initiation (e.g., Ferriday \& Brunstrom, 2011). Although this might seem common sense, very few human studies have examined this possibility. Several conditioning studies in rats and one study in humans have found that exposure to foodassociated stimuli prompts a shorter latency to initiate eating when presented with the opportunity to consume the cued foods (Birch, McPhee, Sullivan, \& Johnson, 1989; Weingarten, 1983). However, to the authors' knowledge, this has not yet been examined in a food cue reactivity paradigm. Eating latency may also reflect a relatively unobtrusive measure of food cue reactivity, as participants may be more likely to be unaware of their eating initiation to be monitored than their actual food intake.

In sum, the PPST and eating initiation might both reflect ecologically valid intake-related measures in food cue reactivity paradigms that can provide insight into important aspects of cueelicited eating and that may overcome some of the limitations of the ad libitum food intake tests. In the current study we aimed to validate the cue-elicited prospective portion size of snack foods and eating initiation by (1) assessing prospective portion size and latency to eat in response to food cue-exposure vs. control exposure, and by (2) correlating PPST and latency scores with commonly used measures in food cue reactivity paradigms (desire to eat, salivation, and ad libitum food intake). We hypothesized that prospective portion size in the cue-exposure condition is increased and that food cue exposed participants start eating more quickly, relative to participants in the control condition. In addition, positive correlations between prospective portion size and desire to eat, salivation and actual food intake were expected, and negative correlations between these measures and eating latency.

\section{Methods}

\subsection{Participants}

Fifty-three female undergraduate students between 18 and 26 years old $(M=20.38, S D=2.07)$ participated in the study in return for course credit or $\mathrm{a} € 5$ gift voucher. Participants were recruited through flyers put up in the university building. The flyers advertised the cover story of the study, which was the influence of sensory processes on perception. After signing up, participants answered some questions to check for eligibility for the study (i.e., female undergraduate students between the age of 18 and 30 with no food allergies). In addition, they were instructed to eat something small (e.g., an apple or a sandwich) $2 \mathrm{~h}$ before participating, but to refrain from eating thereafter. The study was approved by the Ethics Committee of the Faculty of Psychology and Neuroscience of Maastricht University.

\subsection{Measures}

\subsubsection{Food selection}

After signing up for the study, participants received an email in which they were given a list of 8 well-known and generally liked snack foods. They were asked to select their top three of these foods and rank these according to their preference. For each participant, their personal most-preferred food was used throughout the study i.e., if a participant rated milk chocolate as her most favourite food, the PPST, cue exposure, and the taste test were all conducted with milk chocolate. All foods and the frequency with which they were selected in each condition are displayed in Table 1. Participants were instructed not to consume this food in the $24 \mathrm{~h}$ before participating.

\subsubsection{Cue exposure manipulation}

Participants were randomly assigned to either the experimental ( $n=27)$ or the control $(n=26)$ condition. In the experimental condition, participants were instructed to smell their personally preferred food for $2 \mathrm{~min}$. They were told they could look at it, smell it, and touch it, but were not allowed to eat it. Seeing and smelling palatable food has been shown to be an effective way to induce cue reactivity (Boswell \& Kober, 2016). In the control condition, participants smelled small scented soaps for the same amount of time.

\subsubsection{Prospective Portion Size Task (PPST)}

A new PPST was designed as a measure of intended snack food intake. Our PPST is based on the original PPST of Ferriday and Brunstrom (2008) but includes a diverse range of snack foods (see Table 1). In the current study, participants performed the PPST with their highest ranked snack food. Participants are presented with an empty bowl in the middle of a computer screen and they are instructed to fill the bowl with the amount of food they would like to eat at that moment. Pieces of food can be added one-by-one using a slider, and the task is programmed in such a way that it looks 'animated'. To help participants make accurate judgments about the size of the bowl, a real bowl that is identical to the one used in the PPST is placed next to the participant. In addition, the food package of the cued food is presented on the screen next to the bowl. This is done to clarify to the participant which exact food was selected in the task, as participants may vary in their liking of different brands of a snack. Before the actual task takes place, participants complete a practice task in which they fill a bowl with purple and green cubes. Responses are recorded in pieces of food (e.g., number of M\&Ms that are placed in the bowl) which are later converted to kcal. The task was designed in Unity and screenshots are presented in Fig. 1. 
Table 1

The different types of food available in the study and the frequency with which they were selected per condition.

\begin{tabular}{lll}
\hline Food & Experimental condition & Control condition \\
\hline Milk chocolate (Cote D'Or) & 3 & 4 \\
Milk chocolate with hazelnuts (Cote D'Or) & 5 & 2 \\
Dark Chocolate (Cote D'Or) & 5 & 4 \\
Chocolate M\&M's (Mars Inc.) & 3 \\
Peanut M\&M's (Mars Inc.) & 5 & 3 \\
Salty crisps (Lay's) & 0 \\
Paprika crisps (Lay's) & 4 & 8 \\
Cocktail nuts (Duyvis) & 1 & 2 \\
\hline
\end{tabular}

Energy value per $100 \mathrm{~g}$ of each food: Milk chocolate, $535 \mathrm{kcal}$; Milk chocolate with hazelnuts, 560 kcal; Dark chocolate, 530 kcal; Chocolate M\&M's, 468 kcal; Peanut M\&M's, 512 kcal; Salty crisps, 541 kcal; Paprika crisps, 531 kcal; Cocktail nuts, 578 kcal.
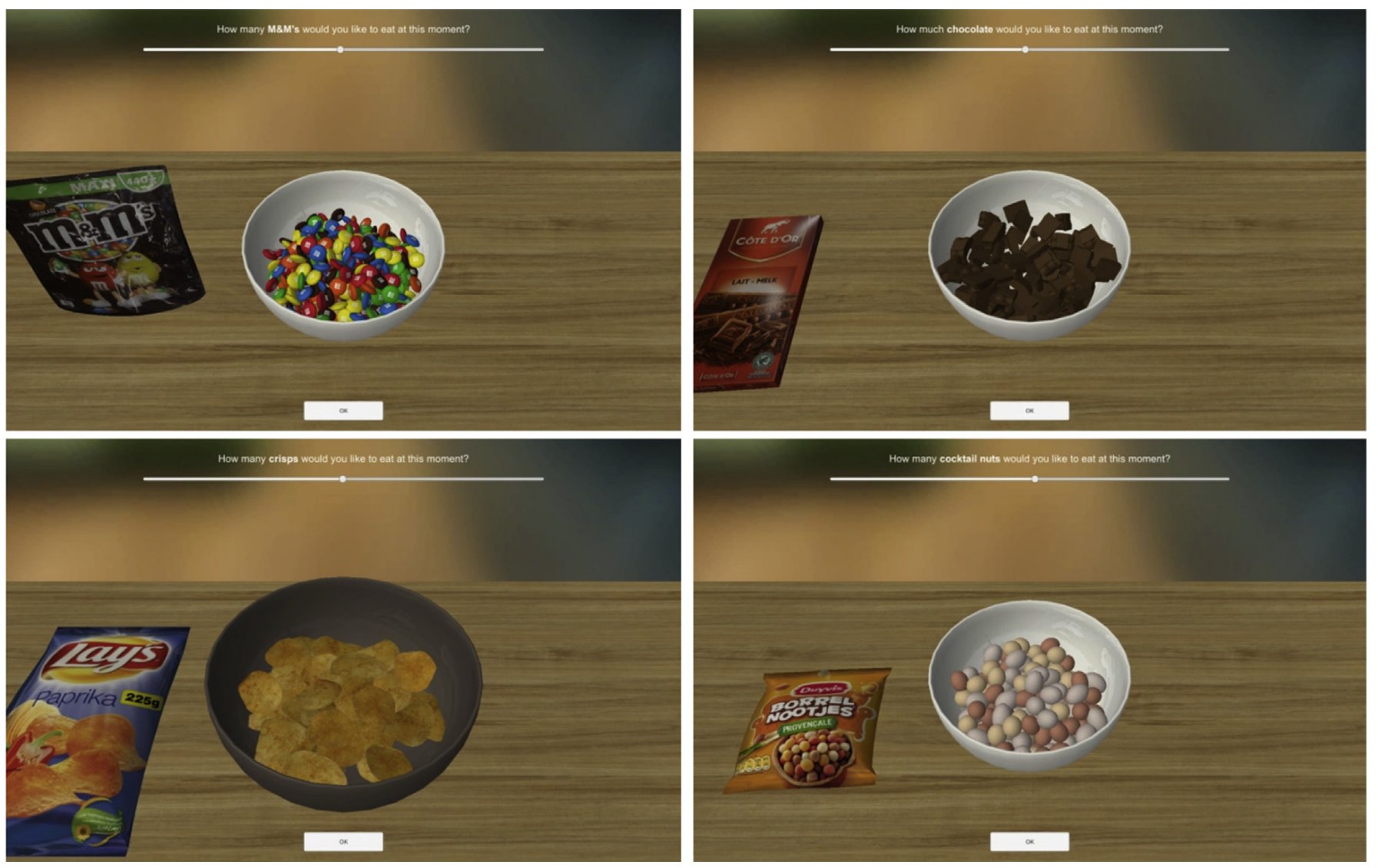

Fig. 1. Screenshots of the Prospective Portion Size Task, showing (from top left to bottom right) chocolate M\&M's, milk chocolate, paprika-flavoured crisps, and cocktail nuts.

\subsubsection{Hunger}

Hunger was measured on a $100 \mathrm{~mm}$ Visual Analogue Scale (VAS). The question read 'how hungry are you at this moment?' and the scale ranged from 0 'not hungry at all' to 100 'extremely hungry'.

\subsubsection{Desire to eat}

Desire to eat was measured on a $100 \mathrm{~mm}$ VAS scale. The question was adjusted to the preferred food of the participant, so that it read 'how much would you like to eat chocolate/crisps/cocktail nuts/M\&Ms (depending on what type of food they had chosen as their preferred food) right now?' The scale ranged from 0 'not at all' to 100 'extremely'.

\subsubsection{Salivation}

Pre-weighed cotton rolls (Hartmann no. 2) were used to measure salivation (Nederkoorn et al., 2000; Peck, 1959). Participants were instructed to put three cotton rolls in their mouth for precisely $1 \mathrm{~min}$. Two cotton rolls were placed in the left and right side of the mouth, between the cheek and lower gums. A third smaller cotton role was placed underneath the tongue. The amount of salivation is reported in grams and was calculated by subtracting the original weight of the cotton rolls from their final weight.

\subsubsection{Food intake}

Participants were presented with a generously filled preweighed bowl with their preferred food (i.e., the same food as used for exposure in the experimental condition). Bowls contained on average $417.32 \mathrm{~g}$ of M\&M's, $82.28 \mathrm{~g}$ of crisps, $287.81 \mathrm{~g}$ of cocktail nuts, and $181.40 \mathrm{~g}$ of chocolate. Participants were told that they received this as a small thank-you for participation and that they could eat as much as they wanted while watching a 10-min TED talk 
(Elora Hardy - Magical houses, made of bamboo). No mention of food intake during the study had been made prior to this presentation of the food. To enhance believability of the cover story, participants filled out a short bogus questionnaire containing 7 questions on the participant's opinion of the TED talk. These items were completed after the video ended. None of the participants consumed all of the presented food.

\subsubsection{Latency to eating}

Participants were unobtrusively filmed during the experiment, in order to assess latency to eating. Films were viewed by two independent raters (PB and $\mathrm{IH}$ ), who timed the duration (in seconds) from the moment the experimenter left the room until the participant first reached for the bowl. The ratings were perfectly correlated $(r>0.99, p<0.001)$ and the ratings of rater $1(\mathrm{~PB})$ were used for analyses.

\subsubsection{External eating and dietary restraint}

Two subscales of the Dutch Eating Behaviour Questionnaire (DEBQ; Van Strien, 2005) were used to measure external eating and dietary restraint. These measures were included to check for random differences between groups, as they have been identified as predictors of desire to eat and food intake after exposure in earlier studies (see for example Burton, Smit, \& Lightowler, 2007; Fedoroff, Polivy, \& Herman, 1997). Both subscales consist of 10 items which are scored on a 5-point Likert scale ranging from 'never' to 'very often'. Example items are 'If you see others eating, do you also feel the desire to eat?' (external eating) and 'When you have eaten too much, do you eat less than usual in the next few days?' (dietary restraint).

\subsubsection{General questionnaire}

The general questionnaire consisted of questions regarding age, adherence to eating instructions, and hypothesis awareness ('What do you think we investigated in this study?').

\subsubsection{Height and weight}

Height and weight were measured using a stadiometer (Seca) and a digital weighing scale. Participants wore light clothing but no shoes.

\subsection{Procedure}

Participants were tested individually between $11 \mathrm{am}$ and $5 \mathrm{pm}$. Upon arriving in the lab, the participant was informed of the alleged aim of the study (i.e., investigating the influence of sensory processes on perception) and filled out an informed consent form. This was followed by the baseline saliva measurement and filling out the hunger VAS. Next, the participant filled out the VAS for desire to eat and performed the baseline PPST. After completion of the baseline measurements, cue exposure with the preferred food (experimental condition) or scented soaps (control condition) took place. Participants were instructed that they were going to smell either food or soaps for $2 \mathrm{~min}$. After $1 \mathrm{~min}$ of exposure, the participant again rated her desire to eat. After $2 \mathrm{~min}$, the post-saliva measurement was completed. In addition, she rated her desire to eat and performed the post-exposure PPST. For the desire ratings and PPST at baseline and after exposure, half of the participants always started with the desire ratings while the other half started with the PPST. The participant was then told that she was going to watch a short TED talk, and that she would receive questions about how much she enjoyed it afterwards. She was also presented with a bowl of her preferred food, ostensibly as a small token of appreciation for participating in the study, and told that she was free to eat from it as much as she wanted to. After the TED talk, the participant filled out a short questionnaire regarding the talk, the DEBQ and the general questionnaire. She was then measured and weighed and received her reimbursement. Finally, she was debriefed about the video recording and asked for her permission to use the data. Full debriefing took place via email after data collection was completed.

\subsection{Statistical analyses}

One participant was excluded from all analyses because she had chosen a food that she was allergic to. Data on desire to eat was missing for one participant. For four participants, there was no data on latency to eat. Because one item of the external eating subscale in our English version of the DEBQ was ambiguously formulated, external eating scores were calculated using the remaining 9 items.

A one-way ANOVA was used to check for baseline differences between groups, as well as for differences in latency to eat and food intake. For the analysis of eating desires, a 2 (condition: experimental vs. control) X 3 (time: baseline vs. during exposure vs. after exposure) mixed ANOVA was conducted. For PPST and salivation, 2 (condition: experimental vs. control) X 2 (baseline vs. after exposure) mixed ANOVAs were carried out. Significant interactions were followed up by analyses of simple effects. Pearson correlation coefficients were computed to establish associations between (cueelicited and/or post measures of) PPST, desire to eat, salivation, latency to eat, and food intake. Correlations within cue-elicited and within post-measures of cue reactivity were both examined because they both provide important but also somewhat different information; correlations among difference scores can provide information about whether cue-elicited changes in different measures of cue reactivity co-occur, and correlations among postmeasures provide information about more general relationships between the different outcome measures including responding not elicited by the cues.

\section{Results}

\subsection{Participant characteristics}

\subsubsection{Group differences}

Participants in the two conditions did not differ on age, BMI, hunger, external eating, or dietary restraint, all $F s<1$, all $p s>0.53$. Means and standard deviations of these variables are provided in Table 2.

\subsubsection{Awareness of hypotheses}

Eighteen participants ( 10 experimental, 8 control; $\chi^{2}(1)=0.34$, $p=0.56$ ) guessed that the study revolved around the relationship between smelling food and eating desires or smelling food and food intake. None of the participants were aware of the latency to eat measurement or the aim of the PPST. Analyses were conducted both with inclusion and exclusion of the aware participants. With the exception of some of the correlations (see the section on Correlations below) results remained the same in both analyses.

\section{Table 2}

Means and standard deviations of participant characteristics per condition.

\begin{tabular}{llllll}
\hline & \multicolumn{2}{l}{$\begin{array}{l}\text { Experimental } \\
\text { condition }(\mathrm{n}=26)\end{array}$} & & \multicolumn{2}{l}{$\begin{array}{l}\text { Control condition } \\
(\mathrm{n}=26)\end{array}$} \\
\cline { 2 - 3 } \cline { 5 - 6 } & $\mathrm{M}$ & $\mathrm{SD}$ & & $\mathrm{M}$ & $\mathrm{SD}$ \\
\hline Age & 20.38 & 1.86 & & 20.38 & 2.30 \\
BMI & 22.49 & 2.34 & & 22.83 & 2.94 \\
Hunger & 61.04 & 21.64 & & 58.27 & 21.16 \\
External eating & 3.38 & 0.47 & & 3.39 & 0.47 \\
Dietary restraint & 2.76 & 0.73 & & 2.88 & 0.68 \\
\hline
\end{tabular}


Therefore, analyses on the full sample are reported.

\subsection{Replication of findings on established cue reactivity measures}

\subsubsection{Desire to eat}

The $2 \times 3$ mixed ANOVA on desire to eat revealed a significant Condition $\times$ Time interaction, $F(1.50,73.47)=24.34, p<0.001$, indicating differential desire ratings over time for the two conditions. Follow-up simple effects analysis showed an increase in desire for the experimental group (baseline, $M=55.85, S D=19.63$; during exposure, $M=69.69, S D=15.21$; post-exposure, $M=68.38$, $S D=16.94 ; F(2,98)=18.56, p<0.001)$, and a decrease in the control group (baseline, $M=61.92, S D=22.59$; during exposure, $M=52.48, S D=21.59$; post-exposure, $M=54.92, S D=20.94 ; F(2$, $98)=7.33, p=0.001$ ). Results are displayed in Fig. 2 .

\subsubsection{Salivation}

The $2 \times 2$ mixed ANOVA on salivation showed no interaction, $F(1,50)=1.95, p=0.17$. In addition, there were no significant main effects for Condition, $F(1,50)=0.21, p=0.65$ or Time, $F(1$, $50)=0.81, p=0.37$. Thus, the two conditions did not differ in their salivation levels, nor did salivation change from baseline to postexposure for either the experimental (baseline, $M=0.91 \mathrm{~g}$, $S D=0.62$; post-exposure, $M=0.94 \mathrm{~g}, S D=0.65$ ) or control group (baseline, $M=1.06 \mathrm{~g}, S D=0.55$; post-exposure, $M=0.94 \mathrm{~g}$, $S D=0.58)$

\subsubsection{Food intake}

The conditions did not differ in their actual food intake (experimental, $M=186.33 \mathrm{kcal}, S D=96.35$, control, $M=221.61 \mathrm{kcal}, S D=126.38 ; F(1,50)=1.28, p=0.26)$.

\subsection{Prospective Portion Size Task}

For the PPST, the $2 \times 2$ mixed ANOVA showed a significant Condition $\times$ Time interaction, $F(1,50)=7.10, p=0.01$. Follow-up simple effects analysis demonstrated that whereas the control group did not change in prospective portion size from baseline $(M=493.15, S D=371.38)$ to post-exposure $(M=468.93$, $S D=377.96), F(1,50)=0.35, p=0.56$, participants in the experimental group showed a significant increase (baseline, $M=404.70$, $S D=380.42$; post-exposure, $M=535.55, S D=440.06$ ), $F(1,50)=10.11, p=0.003$. Differences between conditions at baseline, $F(1,50)=0.72, p=0.40$, and post-exposure, $F(1$, $50)=0.34, p=0.56$ were not significant. Results are shown in Fig. 3.

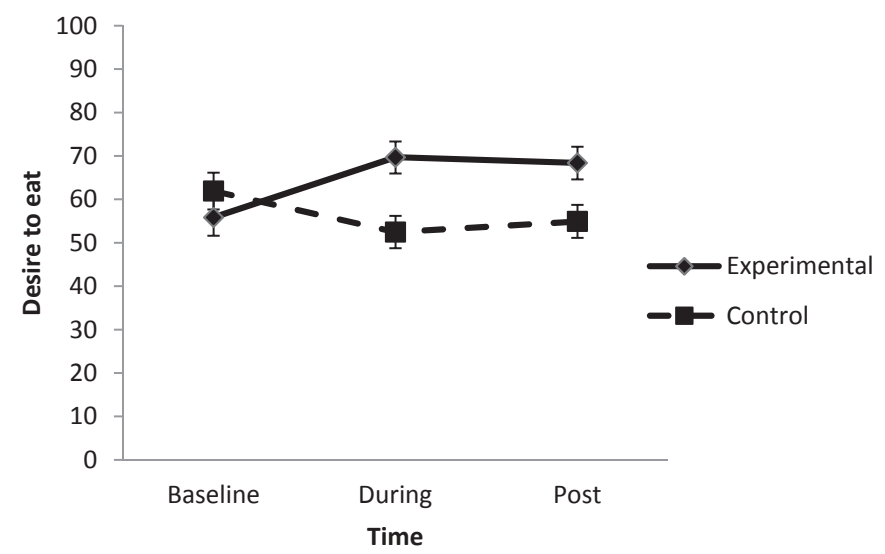

Fig. 2. Self-reported desire to eat (+SEM) in the experimental and control conditions at baseline, during exposure, and after exposure.

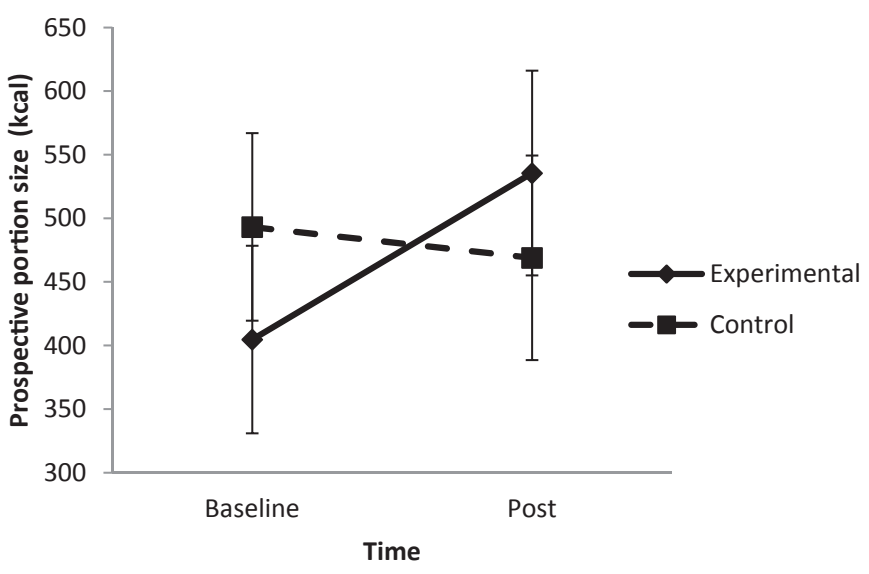

Fig. 3. Prospective portion size ( + SEM) of the participants' most preferred food in the experimental and control conditions at baseline and after exposure.

\subsection{Latency to eating}

The experimental and control groups did not significantly differ on their latency to start eating (experimental, $M=24.29 \mathrm{~s}$, $\mathrm{SD}=40.14$, control, $M=28.34, S D=38.04 ; F(1,47)=0.13, p=0.72)$.

\subsection{Correlations}

Pearson's correlations between all measures were calculated using difference scores (post exposure - pre exposure) as well as post-exposure scores for desire to eat, salivation, and PPST, and post-exposure scores only for ad libitum intake and eating latency. With regard to the difference scores, there was a significant correlation between change in PPST and change in desire to eat. For the post-measures, there were significant correlations between the post-measure of the PPST on the one hand and desire to eat, food intake, and latency to eat on the other hand. In addition, there was a marginally significant correlation between prospective portion size and salivation at the post-measure. Post-exposure desire to eat was negatively correlated with latency to eat. Furthermore, a significant negative association between intake and latency to eat was observed. There were no significant correlations between salivation and any of the other measures, nor between desire to eat and food intake. All correlations are displayed in Table 3. When eighteen participants who were largely aware of the hypotheses were excluded from the analyses, the correlations with latency to eat

Table 3

Correlations between all cue reactivity measures using difference-scores (top half) and post-exposure scores (bottom half) for PPST, desire to eat, and salivation because of missing data, the total number of participants included in the correlations vary $(\mathrm{n}=49-52)$.

\begin{tabular}{|c|c|c|c|c|c|}
\hline & PPST & Desire to eat & Salivation & Food intake & Latency to eat \\
\hline \multicolumn{6}{|c|}{ Difference scores } \\
\hline PPST & - & $0.48^{* *}$ & 0.10 & 0.09 & -0.10 \\
\hline Desire to eat & & - & -0.01 & -0.19 & -0.12 \\
\hline Salivation & & & - & -0.22 & -0.07 \\
\hline Food intake & & & & - & $-0.35^{*}$ \\
\hline Latency to eat & & & & & - \\
\hline \multicolumn{6}{|c|}{ Post-exposure scores } \\
\hline PPST & - & $0.36^{* *}$ & $0.25^{\#}$ & $0.34^{*}$ & $-0.30^{*}$ \\
\hline Desire to eat & & - & 0.07 & 0.04 & $-0.43^{* *}$ \\
\hline Salivation & & & - & 0.07 & 0.04 \\
\hline Food intake & & & & - & $-0.35^{*}$ \\
\hline Latency to eat & & & & & - \\
\hline
\end{tabular}

$\# p=0.077,{ }^{*} p<0.05,{ }^{* *} p<0.01$. 
became non-significant or borderline significant (PPST post exposure, $r=-0.26, p=0.14$; Desire to eat post exposure, $r=-0.33$, $p=0.06$; Intake, $r=-0.25, p=0.16$ ).

\section{Discussion}

The aim of the present study was to validate the new snack food-PPST and eating latency as intake-related measures in a food cue reactivity paradigm in a Dutch female student population. We did this by 1) assessing these measures in response to food cue (vs. neutral cue) exposure, and 2) correlating the measures with commonly used measures in food cue exposure studies (desire to eat, salivation, and ad libitum food intake). It was found that selfreported desire to eat and prospective portion size increased after food cue exposure vs. control (neutral) exposure. Salivation, ad libitum food intake and eating latencies were similar after the food and neutral cue exposure. In addition, correlational analyses indicated that after exposure, larger prospective portion sizes were associated with shorter eating latencies, and both were positively associated with stronger self-reported desires to eat, a greater ad libitum intake, and salivation. Analyses on difference (i.e., post vs. pre exposure) scores only revealed a significant correlation between prospective portion size and self-reported desire to eat.

The finding that prospective portion size of snacks foods increases in response to food cue exposure suggests that it could be a sensitive measure of reactivity to snack foods. This is consistent with previous studies that found increased prospective portion sizes of pizza after pizza exposure (Ferriday \& Brunstrom, 2008, 2011; Tetley et al., 2009, 2010; but see), and suggests that the PPST's sensitivity to food cue exposure extends to common snack foods. Further, post-measures of prospective portion size correlated with the other two behavioural measures that were examined (latency to eat and actual intake), with desire to eat, and (marginally significant) with salivation, though when analysing difference scores (controlling for responding not elicited by the cues), only the correlation with eating desires remained significant. Overall, these data provide initial evidence for this new snack version of the PPST to have concurrent validity. In addition, it is likely that the application of the current snack food PPST is not limited to food cue reactivity paradigms; it seems plausible to assume that it can function as more general measure of appetite (see e.g., Holliday et al., 2014; Wilkinson et al., 2012). Of note, prospective portion size in the current study was, on average, larger than actual food intake (approximately $300 \mathrm{kcal}$ ). It may be that participants experienced a difficulty to estimate exact portion sizes in the PPST (despite efforts to help them do so), or that this reflects a reluctance to eat large amounts of food in the laboratory. Nevertheless, it is thought that prospective portion size reflects an important aspect of real-life eating behaviour due to its role in serving size selection (Brunstrom, 2011).

Although participants were not quicker to start eating after food cue exposure, shorter eating latencies were related to a greater desire to eat, larger total food intake, and increased prospective portion size - though again, regarding analyses on difference scores, only the correlation with intake remained significant. These findings suggest that eating latency is not sensitive to food cue exposure but may be (at least) a correlate of appetite and food cue reactivity. The absence of group differences is surprising: given that conditioned food cues are able to facilitate eating initiation in rats and humans (Birch et al., 1989; Weingarten, 1983), it seems likely that exposure to well-established food cues should have a similar effect. Future studies might consider slight adaptations in the study design to increase the sensitivity of this measure. For example, one could speculate that it may be beneficial not to place the food directly in front of participants but making it less easily accessible (e.g., placing the bowl further away): cue-exposed individuals might be more willing to obtain less easily accessible food more readily compared to individuals not exposed to food cues. This may have the added benefit of reflecting more closely how eating is usually initiated in the natural environment. Of note, after repeating the analyses without hypotheses-aware participants, the correlations with latency to eat remained moderate but were no longer significant. As none of the participants were aware of our latency to eat measurement, it seems unlikely that the significant correlations in the full sample are explained by demand characteristics. Instead, it may be more plausible that the differences are primarily due to the smaller sample size (34 as opposed to 52 participants).

Although increases in salivation and food intake after food cue exposure have been reported previously (e.g., Bulik, Lawson, \& Carter, 1996; Ferriday \& Brunstrom, 2008; Nederkoorn et al., 2000), we did not find such increases despite evidence of successful elicitation of cue reactivity in other measures (desire to eat and prospective portion size). It could be argued that our findings of cue reactivity on subjective - but not objective - measures are a sign of socially desirable answering of the participants. However, as results remained largely similar after exclusion of hypothesisaware participants, and more "objective" measures such as intake have also been shown to be vulnerable to demand characteristics (Robinson et al., 2015), this explanation may not be very likely. Further, this is not the first study failing to find effects of food cue exposure on salivation and/or food intake in healthy participants despite e.g. increases in subjective motivation (e.g., Ferriday \& Brunstrom, 2011; Larsen et al., 2012; Nederkoorn \& Jansen, 2002; Overduin \& Jansen, 1996). This (possible) disconcordance between different cue reactivity measures may not be very surprising given that different response systems are known to be involved in responding to food-associated cues (Delamater \& Oakeshott, 2007), and the fact that correlations between the different reactivity measures were not always present might also be consistent with this. Alternatively, salivation and ad libitum food intake may provide less sensitive measures in food cue reactivity paradigms than eating desires and prospective portion size. Future studies may wish to further investigate the specific circumstances under which food intake and salivation increase after cue exposure.

Given that the prospective portion size and latency to eat measures correlated only moderately (or not at all) with ad libitum food intake, one might argue that these measures are not very valid indices of actual eating behaviour. As outlined in the Introduction, it may be that the two intake-related measures that we aimed to investigate (prospective portion size and latency to eat) actually assess somewhat different aspects of eating behaviour that are not (entirely) captured by ad libitum intake tests, but that are nevertheless important. More specifically, prospective portion size includes pre-meal planning of portion size, which is thought to reflect an important determinant of real-life eating behaviour. Quicker eating latencies may theoretically translate to a more frequent initiation of intake by prompting an individual to engage in eating, potentially resulting in increased daily food intake even in the absence of larger intakes within one meal. Thus, eating behaviour is likely more complex than what is assessed during an ad libitum intake test, and assuming that the different intake-related measures indeed reflect partly different but important aspects of eating behaviour, it might be a good idea to measure multiple indices of intake-related behaviour in future studies.

There are some methodological issues that warrant further discussion, specifically with regard to our food intake measure. First, it could be argued that participants ate because of distraction during the video and that showing effects of cue exposure on top of this might be difficult. Although this is certainly possible, the choice 
of a taste test while watching a video is not unprecedented (Bongers, Jansen, Houben, \& Roefs, 2013; Sheppard-Sawyer, McNally, \& Harnden Fischer, 2000) and was a conscious one as a traditional taste test with a focus on taste, smell and texture of food could also overshadow other effects. For instance, in such traditional taste tests participants are likely to follow instructions (and hence, start tasting) immediately, which would compromise our latency to eat measure. Unfortunately, no studies have investigated potential differences in sensitivity of different intake tests. Second, the order of cue reactivity measures was not counterbalanced, raising the question whether the absence of effects on the intake measure could be due to order effects. It is indeed possible that food cue exposure effects diminish after a few minutes. However, due to the satiety-inducing nature of a taste test it is very common to save food intake for the end of the cue reactivity protocol, and several (but not all) prior studies have found greater cue-elicited food intake after other measures were administered (see for example Fedoroff et al., 1997; Ferriday \& Brunstrom, 2008).

A few limitations of the present study may also be noted. Some of the analyses were underpowered (e.g., between-group differences in food intake), and hence, the present findings should be interpreted with caution and merit replication. Further, since the current study sample consisted primarily of Dutch female students of primarily healthy weight, the generalizability of the findings to other populations has yet to be established. Thus, while this study made a start at testing the validity of two intake-related measures to assess cue reactivity to snack foods, future studies should include larger samples to strengthen the conclusions drawn from the current data. In addition, such studies should include more varied samples (e.g., males, healthy adults of all ages, overweight or obese individuals) in order to generalize results to other populations and not restrict them to healthy female students.

In sum, it is concluded that the new snack food-PPST has potential to be a good measure for food cue reactivity, whereas the usefulness of eating latency as a measure awaits further investigation.

\section{Acknowledgments}

This work was supported by the Netherlands Organisation for Scientific Research (NWO) under Vici Grant 453.10.006, awarded to Anita Jansen. The authors would like to thank Richard Benning and Jacco Ronner for their excellent technical support in developing the PPST.

\section{References}

Birch, L. L., McPhee, L., Sullivan, S., \& Johnson, S. (1989). Conditioned meal initiation in young children. Appetite, 13(2), 105-113.

Bongers, P., Jansen, A., Houben, K., \& Roefs, A. (2013). Happy eating: The Single Target Implicit Association Test predicts overeating after positive emotions. Eating Behaviors, 14, 348-355.
Boswell, R. G., \& Kober, H. (2016). Food cue reactivity and craving predict eating and weight gain: A meta-analytic review. Obesity Reviews, 17(2), 159-177.

Brunstrom, J. M. (2011). The control of meal size in human subjects: A role for expected satiety, expected satiation and premeal planning. Proceedings of the Nutrition Society, 70(02), 155-161.

Brunstrom, J. (2014). Mind over platter: Pre-meal planning and the control of meal size in humans. International Journal of Obesity, 38, S9-S12.

Bulik, C. M., Lawson, R. H., \& Carter, F. A. (1996). Salivary reactivity in restrained and unrestrained eaters and women with buliminia nervosa. Appetite, 27 , 15-24.

Burton, P., Smit, H. J., \& Lightowler, H. J. (2007). The influence of restrained and external eating patterns on overeating. Appetite, 49, 191-197.

Delamater, A. R., \& Oakeshott, S. (2007). Learning about multiple attributes of reward in Pavlovian conditioning. Annals of the New York Academy of Sciences, 1104(1), 1-20.

Fedoroff, I. D. C., Polivy, J., \& Herman, C. P. (1997). The effect of pre-exposure to food cues on the eating behavior of restrained and unrestrained eaters. Appetite, 28 $33-47$.

Ferriday, D., \& Brunstrom, J. M. (2008). How does food-cue exposure lead to larger meal sizes? British Journal of Nutrition, 100(06), 1325-1332.

Ferriday, D., \& Brunstrom, J. M. (2011). 'I just can't help myself: Effects of food-cue exposure in overweight and lean individuals. International Journal of Obesity, 35(1), 142-149.

Holliday, A., Batey, C., Eves, F. F., \& Blannin, A. K. (2014). A novel tool to predict food intake: The Visual Meal Creator. Appetite, 79, 68-75.

Jansen, A. (1998). A learning model of binge eating: Cue reactivity and cue exposure Behaviour Research and Therapy, 36(3), 257-272.

Jansen, A. Havermans, R. C., \& Nederkoorn, C. (2011). Cued overeating. In V. R. Preedy, R. R. Watson, \& C. R. Martin (Eds.), Handbook of behavior, food and nutrition. New York: Springer.

Larsen, J. K., Hermans, R. C., \& Engels, R. C. (2012). Food intake in response to foodcue exposure. Examining the influence of duration of the cue exposure and trait impulsivity. Appetite, 58(3), 907-913.

Nederkoorn, C., \& Jansen, A. (2002). Cue reactivity and regulation of food intake. Eating Behaviors, 3(1), 61-72.

Nederkoorn, C., Smulders, F., \& Jansen, A. (2000). Cephalic phase responses, craving and food intake in normal subjects. Appetite, 35(1), 45-55.

Overduin, J., \& Jansen, A. (1996). Food cue reactivity in fasting and non-fasting subjects. European Eating Disorders Review, 4(4), 249-259.

Peck, R. E. (1959). The SHP test - an aid in the detection and measurement of depression. AMA Archives of General Psychiatry, 1(1), 35-40.

Power, M. L., \& Schulkin, J. (2008). Anticipatory physiological regulation in feeding biology: Cephalic phase responses. Appetite, 50(2-3), 194-206.

Robinson, E., Hardman, C. A., Halford, J. C., \& Jones, A. (2015). Eating under observation: A systematic review and meta-analysis of the effect that heightened awareness of observation has on laboratory measured energy intake. The American Journal of Clinical Nutrition, 102(2), 324-337.

Sheppard-Sawyer, C. L., McNally, R. J., \& Harnden Fischer, J. (2000). Film-induced sadness as a trigger for disinhibited eating. International Journal of Eating Disorders, 28, 215-220.

Tetley, A., Brunstrom, J., \& Griffiths, P. (2009). Individual differences in food-cue reactivity. The role of BMI and everyday portion-size selections. Appetite, 52(3), 614-620.

Tetley, A., Brunstrom, J., \& Griffiths, P. (2010). The role of sensitivity to reward and impulsivity in food-cue reactivity. Eating Behaviors, 11(3), 138-143.

Van Strien, T. (2005). Nederlandse Vragenlijst voor Eetgedrag 2005. Handleiding en Verantwoording [Manual of the Dutch Eating Behavior Questionnaire 2005] Amsterdam: Boom test uitgevers.

Weingarten, H. P. (1983). Conditioned cues elicit feeding in sated rats: A role for learning in meal initiation. Science, 220(4595), 431-433.

Wilkinson, L. L., Hinton, E. C., Fay, S. H., Ferriday, D., Rogers, P. J., \& Brunstrom, J. M. (2012). Computer-based assessments of expected satiety predict behavioural measures of portion-size selection and food intake. Appetite, 59, 933-938.

Zoon, H. F. A., He, W., de Wijk, R. A., de Graaf, C., \& Boesveldt, S. (2014). Food preference and intake in response to ambient odours in overweight and normal-weight females. Physiology \& Behavior, 133, 190-196. 